\title{
Physician practice in food allergy prevention in the Middle East and North Africa
}

\author{
Yvan Vandenplas ${ }^{1}$, Abdulrahman Saleh AlFrayh ${ }^{2}$, Bandar AlMutairi ${ }^{3}$, Mahmoud Salah Elhalik ${ }^{4}$, Robin J. Green ${ }^{5}$, \\ Joseph Haddad ${ }^{6}$, Emad Abdulqader Koshak', Mohamad Miqdady ${ }^{8}$, Nezha Mouane $^{9}$, Mohamed Salah ${ }^{10}$, \\ Gamal Samy ${ }^{11}$, Marzieh Tavakol ${ }^{12}$, Andrea von Berg $^{13}$ and Hania Szajewska ${ }^{14^{*}}$
}

\begin{abstract}
Background: A number of scientific organisations have developed guidelines for the primary prevention of allergic disease through nutritional interventions. However, even if the best evidence-based guidelines are available, these guidelines do not necessarily lead to adherence and improved health outcomes.

Method: To determine how closely the practice of physicians in select Middle Eastern and North African countries compares with the current recommendations on the primary prevention of allergy a survey study was performed using a structured questionnaire and convenience sampling.

Results: A total of 1481 physicians responded, of which $66.1 \%$ were pediatricians. A total of $76.6 \%$ of responding physicians routinely identify infants who are at risk for developing allergy. In infants at risk for developing allergy, 89.1\% recommend exclusive breastfeeding for at least 4 months. In contrast to current recommendations, 51.6\% routinely recommend avoidance of any allergenic food in the lactating mother. In infants at risk of developing allergy who are completely formula fed, standard infant formula was recommended by $22.5 \%$ of responders. Of the responding physicians, $50.6 \%$ would recommend delaying the introduction of complementary food in infants at risk of allergy compared to those not at risk, whereas $62.5 \%$ would recommend postponing the introduction of potentially allergenic foods. Only 6.6\% stated they follow all current recommendations on food allergy prevention.

Conclusion: The results of this survey suggest that a substantial part of responding physicians from select Middle Eastern and North African (MENA) countries do not follow current recommendations on primary prevention of allergic disease through nutritional interventions.
\end{abstract}

Keywords: Allergy, atopy, prevention, breastfeeding, hydrolysed formula, complementary feeding

\section{Background}

The rising number of children and adults with allergic disorders such as asthma, allergic rhinitis, atopic dermatitis and food allergy worldwide is a major public health concern [1]. The origins of this increase are still not well understood. However, it has been hypothesised that factors such as the mode of delivery (vaginal vs caesarean), aberrant gut microbiota, use of antibiotics in the early neonatal period, mode of feeding (breast vs formula feedings) and mode of weaning (early vs later) contribute

\footnotetext{
* Correspondence: hania@ipgate.pl

${ }^{14}$ The Medical University of Warsaw, Warsaw, Poland

Full list of author information is available at the end of the article
}

to the development of allergic diseases. If so, the prevention of allergic disorders through modification of early nutritional interventions is of great interest.

A number of scientific organisations have developed guidelines for the primary prevention of allergic disease through nutritional interventions [2-5]. Maternal avoidance diets that avoid foods such as milk and eggs during pregnancy and lactation were previously recommended [6], but this is not the recommendation of recent guidelines [2-5]. For all infants, exclusive breastfeeding for up to 6 months is a desirable goal [3]. Infants with a documented hereditary risk of allergy (i.e., an affected parent and/or sibling), who cannot be breastfed exclusively, 
should receive either a partially or extensively hydrolysed formula as a means of preventing allergic reactions. There is no convincing scientific evidence that avoidance or delayed introduction of potentially allergenic foods beyond 4-6 months reduces allergies in infants considered to have an increased risk for developing allergic diseases or in those not considered to have an increased risk.

Even if the best evidence-based guidelines are available, they do not necessarily lead to improved health outcomes. Hence, there is an interest in knowledge translation. A number of barriers between guidelines (or other research) and health outcomes exist. They extend from awareness to adherence [7]. Overall, we have limited knowledge on the practices provided to patients for the primary prevention of allergic diseases. The purpose of this survey study was to determine how closely the practice of physicians in select MENA countries compare with current recommendations on primary prevention of allergy.

\section{Methods}

The questionnaire was developed by a working group of experts in the field of allergy prevention and members of the target population with reference to existing research literature. The working group comprised regional experts from representative countries across the MENA region including Egypt, Iran, Kingdom of Saudi Arabia, Kuwait, Lebanon, Morocco and the United Arab Emirates. These regional experts worked in consultation with international experts from Belgium, Germany, Poland and South Africa. It was also developed in collaboration with Nestlé Nutrition Institute Middle East during a meeting in Dubai in January 2015.

The questionnaire consisted of two parts. The first part focused on responders' characteristics. The second part of the questionnaire included specific closed questions (i.e. response options were available) with regard to an infant at high-risk of allergy (Additional file 1). This has been defined as an infant without allergic symptoms but with at least one first-degree relative (parent or sibling) having one or more allergic disease (i.e. allergic rhinitis, asthma, urticaria, atopic dermatitis [eczema], food allergy) [4]. The allergic disease should have been diagnosed by a physician or the patient must be clearly dependant on a relevant treatment. The language of the questionnaire was in English or French (in Algeria and Morocco). Institutional review board approval was obtained from each participating centre prior to study commencement.

The survey assessed adherence to practice recommended by international guidelines which can be summarised that $[3,4,8,9]$ :
- infants should be assessed for allergy risk

- infants should be exclusively breastfed for at least 4 months

- maternal diet of lactating mothers should not avoid potential allergens

- formula-fed infants at risk of developing allergy should be fed a formula clinically proven to have reduced allergenicity

- infants at risk of allergy should not have delayed introduction of complementary feeding or potentially allergenic complementary foods

Convenience sampling was employed to collect data. Surveys were distributed at national and regional paediatric meetings in the MENA region, including ELITE Conference, Lebanese Pediatric Society Meeting, UMEMPS Meeting, Mediterranean Congress of Pediatrics, Egyptian Society for Neonatal and Preterm Care Meeting, and Arab Neonatal Conference. Surveys were completed anonymously. Descriptive statistics were used to summarise the demographics of the respondents and their responses to questions.

\section{Results}

Two thousand surveys were distributed. A total of 1572 surveys were completed, with 19 surveys excluded due to allergy practice not being adequately completed and an additional 72 excluded because they were from unspecified or non-relevant healthcare specialities. Therefore, the total number of responders was 1481 (Additional file 2). Of these surveys, 1100 were completed at national meetings, and 381 were completed at regional meetings. The characteristics of participating physicians are presented in Table 1 . The majority of participants were below 40 years of age and only 3.3\% of respondents were over 60 years of age. The male to female ratio was approximately $1: 1$ (53.9\% vs $46.1 \%$, respectively). Within the sample, 979 (66.1\%) were paediatricians, $341(23.0 \%)$ were general physicians, 105 (7.1\%) were paediatric gastroenterologists and $56(3.8 \%)$ were classified as others. The majority of participants, $1048(70.8 \%)$, reported working within the government facility, $422(28.5 \%)$ reported working in a private facility and $11(0.7 \%)$ reported working in other practices. Most participants 1294 (90.7\%) worked full time.

The most represented countries were Saudi Arabia (36.0\%), Morocco (26.2\%), Lebanon (9.4\%), Algeria (8.0\%), Egypt (5.8\%), Iran (4.8\%), Iraq (3.0\%) and Kuwait $(2.6 \%)$. For the remaining countries, the response was below $1 \%$ (Table 1 ).

A total of $76.6 \%$ of responding physicians routinely identify infants at risk for developing allergy and $89.1 \%$ recommend exclusive breastfeeding for at least 4 months. In addition, $51.6 \%$ routinely recommend 
Table 1 The demographic and self-reported characteristics of the survey respondents $(N=1481)$

\begin{tabular}{|c|c|c|c|}
\hline Demographic & Category & Number & Percent \\
\hline \multirow[t]{4}{*}{ Specialty $(N=1481)$} & Paediatricians & 979 & 66.1 \\
\hline & General physicians & 341 & 23.0 \\
\hline & Paediatric gastroenterologists & 105 & 7.1 \\
\hline & Others & 56 & 3.8 \\
\hline \multirow[t]{3}{*}{ Practice type $(N=1481)$} & Governmental & 1048 & 70.8 \\
\hline & Private & 422 & 28.5 \\
\hline & Others & 11 & 0.7 \\
\hline \multirow[t]{3}{*}{ Practice location $(N=1471)$} & Hospital only & 957 & 65.1 \\
\hline & Clinic only & 447 & 30.4 \\
\hline & Others & 67 & 4.6 \\
\hline \multirow[t]{2}{*}{ Work status $(N=1427)$} & Full time & 1294 & 90.7 \\
\hline & Part time & 133 & 9.3 \\
\hline \multirow[t]{9}{*}{ Country $(N=1448)$} & Saudi Arabia & 521 & 36.0 \\
\hline & Morocco & 380 & 26.2 \\
\hline & Lebanon & 136 & 9.4 \\
\hline & Algeria & 116 & 8.0 \\
\hline & Egypt & 84 & 5.8 \\
\hline & Iran & 69 & 4.8 \\
\hline & Iraq & 43 & 3.0 \\
\hline & Kuwait & 38 & 2.6 \\
\hline & Others & 61 & 4.2 \\
\hline \multirow[t]{2}{*}{ Gender $(N=1466)$} & Male & 790 & 53.9 \\
\hline & Female & 676 & 46.1 \\
\hline \multirow[t]{4}{*}{ Age group $(N=1467$ ) } & $<40$ years & 597 & 40.7 \\
\hline & $40-50$ years & 504 & 34.4 \\
\hline & $50-60$ years & 317 & 21.6 \\
\hline & $>60$ year & 49 & 3.3 \\
\hline
\end{tabular}

avoidance of any allergenic food in the lactating mother. In an infant at risk of developing allergy who is both breast and formula fed (mixed feeding), 25.0\% of physicians would recommend standard infant formula, whereas $69 \%$ would recommend a partial or extensive hydrolysate formula. In an at-risk infant who is completely formula fed, $22.5 \%$ of physicians would recommend standard infant formula, whereas $71.1 \%$ would recommend a partial or extensive hydrolysate formula. Of the responding physicians, $50.6 \%$ would recommend delaying the introduction of complementary food and $62.5 \%$ would recommend postponing the introduction of potentially allergenic foods. Only $6.6 \%$ of respondents self-reported following all current recommendations on the primary prevention of allergy as per the recommendations summarised in the methodology (Table 2). There were no meaningful differences between specialities, with only $6.1 \%$ of paediatricians, and $7.6 \%$ of pediatric gastroenterologists selfreporting that they follow all current recommendations.

\section{Discussion}

\section{Principal findings}

The survey responses suggest that the majority of participating physicians from these select MENA countries routinely identify infants at risk for developing allergy. The recommendation for allergy prevention that is most commonly followed was exclusive breastfeeding for at least 4 months. Contrary to current recommendations, avoidance of any allergenic food in the lactating mother is often recommended, and a substantial number of physicians appear to still recommend standard infant formula in infants who are both breast and formula fed or who are exclusively formula fed. These data suggest a large number of physicians are following outdated recommendations, such as the 2000 American Academy of Pediatrics guidelines, which advise maternal avoidance diets for prevention. [6] These guidelines have been superseded by guidelines that no longer make this recommendation. $[3,4]$ Over $50 \%$ of physicians would 
Table 2 Questionnaire results

\begin{tabular}{|c|c|c|c|c|c|c|c|c|c|c|c|c|}
\hline \multirow[t]{2}{*}{ Question } & \multicolumn{4}{|c|}{ All physicians } & \multicolumn{4}{|c|}{ Pediatricians } & \multicolumn{4}{|c|}{ Pediatric Gastroenterologists } \\
\hline & $\mathrm{N}$ & $n$ & & $\%$ & $\mathrm{~N}$ & $n$ & & $\%$ & $\mathrm{~N}$ & $\mathrm{n}$ & & $\%$ \\
\hline \multirow[t]{2}{*}{ Do you routinely identify infants at risk for developing allergy? } & 1476 & Yes & 1130 & 76.6 & 975 & Yes & 747 & 76.6 & 105 & Yes & 76 & 72.4 \\
\hline & & No & 346 & 23.4 & & No & 228 & 23.4 & & No & 29 & 27.6 \\
\hline \multirow{2}{*}{$\begin{array}{l}\text { In an infant at risk for developing allergy, do you recommend exclusive } \\
\text { breastfeeding for at least } 4 \text { months? }\end{array}$} & 1471 & Yes & 1310 & 89.1 & 972 & Yes & 859 & 88.4 & 105 & Yes & 95 & 90.5 \\
\hline & & No & 161 & 10.9 & & No & 113 & 11.6 & & No & 10 & 9.5 \\
\hline \multirow{2}{*}{$\begin{array}{l}\text { In an infant at risk for developing allergy, who is exclusively breast fed, } \\
\text { do you routinely recommend avoidance of any of the allergenic foods } \\
\text { (cow's milk, egg, fish, peanut, soy, wheat) in the lactating mother? }\end{array}$} & 1462 & Yes & 754 & 51.6 & 965 & Yes & 548 & 56.8 & 105 & Yes & 33 & 31.4 \\
\hline & & No & 708 & 48.4 & & No & 417 & 43.2 & & No & 72 & 68.6 \\
\hline \multicolumn{13}{|l|}{$\begin{array}{l}\text { In an infant at risk for developing allergy, who is breast and formula } \\
\text { fed (mix feeding), which type of formula do you recommend? }\end{array}$} \\
\hline - Standard (regular) infant formula & 1458 & 365 & & 25.0 & 961 & 211 & & 22.0 & 105 & 33 & & 31.4 \\
\hline • pH formula (HA formula) & & 890 & & 61.0 & & 605 & & 63.0 & & 58 & & 55.2 \\
\hline - Extensively hydrolysed formula & & 117 & & 8.0 & & 87 & & 9.1 & & 10 & & 9.5 \\
\hline - Soy infant formula & & 57 & & 3.9 & & 42 & & 4.4 & & 2 & & 1.9 \\
\hline - Other & & 23 & & 1.6 & & 15 & & 1.6 & & 2 & & 1.9 \\
\hline - Combination of formula & & 6 & & 0.4 & & 1 & & 0.1 & & 0 & & 0 \\
\hline \multicolumn{13}{|l|}{$\begin{array}{l}\text { In an infant at risk for developing allergy, who is exclusively formula, } \\
\text { which type of formula do you recommend? }\end{array}$} \\
\hline - Standard (regular) infant formula & 1424 & 320 & & 22.5 & 939 & 183 & & 19.5 & 104 & 38 & & 36.5 \\
\hline - $\mathrm{pH}$ formula (HA formula) & & 822 & & 57.7 & & 533 & & 56.8 & & 55 & & 52.9 \\
\hline - Extensively hydrolysed formula & & 191 & & 13.4 & & 148 & & 15.8 & & 10 & & 9.6 \\
\hline - Soy infant formula & & 73 & & 5.1 & & 61 & & 6.5 & & 0 & & 0 \\
\hline - Other & & 14 & & 1.0 & & 10 & & 1.1 & & 1 & & 1.0 \\
\hline - Combination of formula & & 4 & & 0.3 & & 4 & & 0.4 & & 0 & & 0 \\
\hline \multirow{2}{*}{$\begin{array}{l}\text { In an infant at risk for developing allergy, do you recommend } \\
\text { delaying the introduction of complementary foods compared } \\
\text { with non-at-risk infants? }\end{array}$} & 1444 & Yes & 731 & 50.6 & 950 & Yes & 495 & 52.1 & 104 & Yes & 53 & 51.0 \\
\hline & & No & 713 & 49.4 & & No & 455 & 47.9 & & No & 51 & 49.0 \\
\hline \multirow{2}{*}{$\begin{array}{l}\text { In an infant at risk for developing allergy, do you recommend } \\
\text { postponing the introduction of potentially allergenic foods } \\
\text { (egg, cow's milk, wheat, fish, peanut) compared with non-at-risk infants? }\end{array}$} & 1434 & Yes & 896 & 62.5 & 942 & Yes & 576 & 61.1 & 103 & Yes & 65 & 63.1 \\
\hline & & No & 538 & 37.5 & & No & 366 & 38.9 & & No & 38 & 36.9 \\
\hline \multirow[t]{2}{*}{ Follow all current recommendations on primary prevention of allergy } & 1481 & Yes & 98 & 6.6 & 979 & Yes & 60 & 6.1 & 105 & Yes & 8 & 7.6 \\
\hline & & No & 1383 & 93.4 & & No & 919 & 93.9 & & No & 97 & 92.4 \\
\hline
\end{tabular}

HA hypo-allergenic, $p H$ partially hydrolysed

recommend delaying the introduction of complementary food, and over $60 \%$ would recommend postponing the introduction of potentially allergenic foods. Current guidelines encourage timely introduction of complementary food $[3,4]$. Only $6.6 \%$ of responders self-reported following all current recommendations on the primary prevention of allergy.

\section{Strengths and weaknesses of the study}

This survey provides an up-to-date overview on the current state of allergy prevention practice in select MENA countries. However, the sample sizes for many of these countries were not representative.

The survey method was not entirely robust. The study is limited by its convenience sample and its inability to generalise to participants other than those studied.
Practitioners who provided our data were not selected through a randomisation process. We also accept that there remains the potential for a response bias because those who do not advise on allergy prevention may be less likely to complete the survey. Additionally no steps were taken to ensure that a physician was not able to take the survey twice.

The survey documented only the physicians' selfreported management of an infant at risk for developing an allergy. However, we did not investigate actual practice in the countries involved. Furthermore, we realise that because of the different healthcare systems in many countries, the nature and role of each type of physician may vary considerably. Access to specialised formulas may also differ depending on the country and healthcare system. 
The analysis of the questionnaires does not allow us to conclude on the reasons for failure to comply with recommendations, and therefore does not suggest specific interventions. One explanation for the lack of knowledge of respondents may have been that some of these were physicians who were usually not expected to provide allergy prevention advice.

\section{Comparisons with other studies}

One study from Brazil on the knowledge and practice of physicians and nutritionists regarding the prevention of food allergy has shown similar results [10]. Only some of the recommendations issued by scientific organisations were followed in practice. Most of the discrepancies between recommendations and practice, as with the present study, were in the timings of the introduction of complementary feeding and the avoidance of potentially allergenic foods. The study concluded that there are gaps in knowledge among healthcare providers regarding the prevention of food allergy. A recent French study confirmed these gaps, as hydrolysates are not prescribed in all units [11].

\section{Conclusions}

We have provided an important, albeit preliminary, insight into the routine provision of primary prevention of allergy advice within select MENA countries. The results of our survey suggest that a substantial part of responding physicians from this region do not follow current recommendations on allergy prevention in infants at risk of allergy. The findings of this survey may suggest that more educational efforts are required to increase the awareness and/or the adherence to current guidelines.

\section{Additional files}

Additional file 1: Survey questionnaire in English. (PDF $23 \mathrm{~kb}$ )

Additional file 2: Survey data tables. (PDF $41 \mathrm{~kb}$ )

\section{Abbreviations}

HA: Hypo-allergenic; MENA: Middle East and North Africa; pH: Partially hydrolysed

\section{Acknowledgements \\ Medical writing support was provided by Dr. Marcus Corander of OPEN Health Dubai and was funded by Nestlé Nutrition Institute Middle East. Statistical analysis was performed by Leonard Kauffman of Data Investigation Company Europe (DICE) and funded by Nestlé Nutrition Institute Middle East. Authors attending the meeting for questionnaire development received support and honoraria from Nestlé Nutrition Institute Middle East. The authors would like to acknowledge the contribution of Dr. Hassan Alrayes and Dr. Haya Kamfer in distribution and collection of surveys.}

\section{Funding}

Nestlé Nutrition Institute Middle East provided support and honoraria for all the authors who attended the meeting for questionnaire development, they also funded the medical writing and data analysis support. The authors were collectively responsible for the study design as well as the analysis and interpretation of data and the writing of the manuscript.

\section{Availability of data and materials}

Questionnaire and data tables available as online supplementary information.

\section{Authors' contributions}

Y , ASA, BM, MSE, RJG, JH, EAK, MM, NM, MS, GS, MT, AVB and HS developed the survey questionnaire. ASA, BM, MSE, JH, EAK, MM, NM, MS, GS and MT disseminated the survey and collected data. HS and $Y$ wrote the first draft of the paper. YV, ASA, BM, MSE, RJG, JH, EAK, MM, NM, MS, GS, MT, AVB and $\mathrm{HS}$ contributed to discussion of the results, review of the manuscript and approved the final manuscript.

\section{Competing interests}

The authors declare that they have no competing interests.

\section{Consent for publication}

Not applicable.

Ethics approval and consent to participate

Ethics and IRB approval was granted from the Institute of Postgraduate Childhood Studies, Ain Shams University, Cairo, Egypt. Written informed consent waiver was received prior to study initiation. Completion of the questionnaire constituted assumed consent to participate from the responding physicians.

\section{Publisher's Note}

Springer Nature remains neutral with regard to jurisdictional claims in published maps and institutional affiliations.

\section{Author details}

${ }^{1}$ Department of Pediatrics, UZ Brussel, Vrije Universiteit Brussel, Brussels, Belgium. ${ }^{2}$ Department of Pediatrics, King Saud University College Of Medicine, Riyadh, Kingdom of Saudi Arabia. ${ }^{3}$ Bandar Medical Center, Jahra City, Kuwait. ${ }^{4}$ Department of Pediatrics and Neonatology, Latifa Hospital, Dubai Health Authority, Dubai, UAE. ${ }^{5}$ Department of Paediatrics and Child Health, University of Pretoria, Pretoria, South Africa. ${ }^{6}$ Department of Pediatrics, Saint George University Hospital, Balamand University, Beirut, Lebanon. ${ }^{7}$ Department of Internal Medicine, King Abdulaziz University Hospital, Jeddah, Kingdom of Saudi Arabia. ${ }^{8}$ Pediatric Gastroenterology, Hepatology \& Nutrition Division, Sheikh Khalifa Medical City, Abu Dhabi, United Arab Emirates. ${ }^{9}$ Gastroenterology Nutrition Department, Children Hospital Ibn Sina, University Mohammed V Faculty of Medicine, Rabat, Morocco. ${ }^{10}$ Nestlé Nutrition, Dubai, United Arab Emirates. ${ }^{11}$ Department of Medical Childhood Studies, Institute of Postgraduate Childhood Studies, Ain Shams University, Cairo, Egypt. ${ }^{12}$ Department of Allergy and Clinical Immunology, Shahid Bahonar Hospital, Alborz University of Medical Sciences, Karaj, Iran. ${ }^{13}$ Department of Paediatrics, Research Institute,

Marien-Hospital-Wesel, Wesel, Germany. ${ }^{14}$ The Medical University of Warsaw, Warsaw, Poland.

Received: 13 May 2016 Accepted: 25 April 2017

Published online: 05 May 2017

References

1. Asher MI, Montefort S, Bjorksten B, Lai CK, Strachan DP, Weiland SK, Williams $\mathrm{H}$, Group IPTS. Worldwide time trends in the prevalence of symptoms of asthma, allergic rhinoconjunctivitis, and eczema in childhood: ISAAC Phases One and Three repeat multicountry cross-sectional surveys. Lancet. 2006; 368(9537):733-43

2. Fleischer DM, Spergel JM, Assa'ad AH, Pongracic JA. Primary prevention of allergic disease through nutritional interventions. J Allergy Clin Immunol Pract. 2013;1(1):29-36.

3. Nutrition ECo, Agostoni C, Braegger C, Decsi T, Kolacek S, Koletzko B, Michaelsen KF, Mihatsch W, Moreno LA, Puntis J, et al. Breast-feeding: A commentary by the ESPGHAN Committee on Nutrition. J Pediatr Gastroenterol Nutr. 2009;49(1):112-25

4. Greer FR, Sicherer SH, Burks AW, American Academy of Pediatrics Committee on N, American Academy of Pediatrics Section on A, Immunology. Effects of early nutritional interventions on the development of atopic disease in infants and children: the role of maternal dietary restriction, breastfeeding, timing of introduction of complementary foods, and hydrolyzed formulas. Pediatrics. 2008;121(1):183-91. 
5. Section on B. Breastfeeding and the use of human milk. Pediatrics. 2012 129(3):e827-41.

6. American Academy of Pediatrics. Committee on Nutrition. Hypoallergenic infant formulas. Pediatrics. 2000;106(2 Pt 1):346-9.

7. Glasziou P, Haynes B. The paths from research to improved health outcomes. ACP J Club. 2005;142(2):A8-10.

8. Muraro A, Halken S, Arshad SH, Beyer K, Dubois AE, Du Toit G, Eigenmann PA, Grimshaw KE, Hoest A, Lack G, et al. EAACl food allergy and anaphylaxis guidelines. Primary prevention of food allergy. Allergy. 2014;69(5):590-601.

9. Sampson HA, Aceves S, Bock SA, James J, Jones S, Lang D, Nadeau K, Nowak-Wegrzyn A, Oppenheimer J, Perry TT, et al. Food allergy: a practice parameter update-2014. J Allergy Clin Immunol. 2014;134(5):1016-25:e1043.

10. Ribeiro CC, Leite Speridiao Pda G, de Morais MB. Knowledge and practice of physicians and nutritionists regarding the prevention of food allergy. Clin Nutr. 2013;32(4):624-9.

11. Chouraqui JP, Simeoni U, Tohier C, Nguyen F, Kempf C, Beck L, Lachambre E. Screening for the risk of allergy and prevention in French maternity units: A survey. Arch Pediatr. 2015;22(9):943-50.

Submit your next manuscript to BioMed Central and we will help you at every step:

- We accept pre-submission inquiries

- Our selector tool helps you to find the most relevant journal

- We provide round the clock customer support

- Convenient online submission

- Thorough peer review

- Inclusion in PubMed and all major indexing services

- Maximum visibility for your research

Submit your manuscript at www.biomedcentral.com/submit
Biomed Central 